COLORECTAL CANCER

\title{
Incidence and recurrence rates of colorectal adenomas estimated by annually repeated colonoscopies on asymptomatic Japanese
}

\author{
Y Yamaji, T Mitsushima, H Ikuma, H Watabe, M Okamoto, T Kawabe, R Wada, H Doi, M Omata
}

Gut 2004;53:568-572. doi: 10.1136/gut.2003.026112

\begin{abstract}
Background: Whereas high recurrence rates of colorectal adenomas after polypectomy are widely recognised, little is known of the natural incidence in those with no neoplastic lesions initially. It is also known that single colonoscopy has a significant miss rate.

Aims: To elucidate the incidence and recurrence rates of colorectal neoplasms from a large cohort of asymptomatic Japanese patients on the basis of annually repeated colonoscopies.

Methods: A total of 6225 subjects (4659 men and 1566 women) participating in an annual colonoscopic screening programme and completing three or more colonoscopies were analysed during the 14 year period between 1988 and 2002. Patients were divided into three groups according to the findings of the initial two colonoscopies: 4084 subjects with no neoplasm, 1818 with small adenomas $<10 \mathrm{~mm}$, and 323 with advanced lesions, including carcinoma in situ, severe dysplasia, or large adenomas $\geqslant 10 \mathrm{~mm}$. Mean age at the second colonoscopy was 48.8 years.

Results: For all types of colorectal neoplasms, the incidence rate in those with no initial neoplasm was $7.2 \%$ /year whereas recurrence rates in those with small adenomas and advanced lesions were $19.3 \%$ and $22.9 \%$ /year, respectively. For advanced colorectal lesions, the incidence rate was $0.21 \%$ /year whereas recurrence rates in those with small adenomas and advanced lesions were $0.64 \%$ and $1.88 \%$ /year, respectively. Colorectal neoplasms were in general more likely to develop in males and older subjects.

Conclusions: Although recurrence rates after polypectomy were elevated, the incidence rates in subjects with no neoplastic lesions initially were quite high.
\end{abstract}

See end of article for authors' affiliations

Correspondence to: Dr Y Yamaji, Second Department of Internal Medicine, Faculty of Medicine, University of Tokyo, 7-3-1 Hongo, Bunkyo-ku, Tokyo 113 8655, Japan;

yamaji-tky@umin.ac.jp

Accepted for publication 28 October 2003
C olorectal adenomas are reputed to be precancerous lesions that develop into colorectal cancers on the basis of the adenoma-carcinoma sequence. ${ }^{12}$ The effects of screening for colorectal cancer and removing precancerous lesions or early stage cancers on the prevention of colorectal cancer development or death have been established. ${ }^{3-6}$ Because of the high recurrence rates of colorectal adenomas in patients who have undergone polypectomy, regular surveillance by colonoscopy has been recommended..$^{8}$

On the other hand, colorectal adenomas are much more common lesions than colorectal cancers, and tiny colorectal adenomas are frequently discovered by particularly vigorous colonoscopy. ${ }^{9-12}$ In this regard, recent prevalence studies based on screening colonoscopy of asymptomatic adults have reported colorectal adenomas in approximately 30\% of patients aged $>50$ years whereas the prevalence of invasive cancer is less than $1 \% .^{1011} 13$

Regarding the new development of colorectal adenomas, there have been many reports on the recurrence rates of colorectal adenomas after polypectomy. ${ }^{74-17}$ However, reports on the incidence rates of colorectal adenomas from subjects free of neoplastic lesions on initial colonoscopy are scarce, and the sample sizes of the few previous studies were rather small. ${ }^{18} 19$

In this study, we aimed to determine the actual incidence rates of colorectal adenomas from a large cohort that was initially adenoma free. To obtain precise rates, repeated annual colonoscopies were conducted. As it is known that single colonoscopy has a significant miss rate, ${ }^{20-22}$ the initial colorectal findings were confirmed by the second of two serial colonoscopies. Hence analysis was based on at least the third or even later colonoscopy. Then, the incidence rates were compared with recurrence rates after polypectomy. Our results should represent fundamental data that can be used for the study of colorectal neoplasms and the planning of cancer prevention programmes.

\section{METHODS \\ Subjects}

We consecutively enrolled asymtomatic Japanese subjects who underwent total colonoscopy as part of their annual medical health checkup at Kameda General Hospital and Makuhari Clinic between 1988 and 2002. They had no visible rectal bleeding, recent change in bowel habits, or recent or current lower abdominal pain. They had not been screened by faecal occult blood tests or other examinations for colorectal cancer, and they underwent colonoscopy as the first choice examination to check for colorectal lesions. Subjects with a personal history of colorectal cancer, colorectal polyps, or inflammatory bowel disease were excluded. All subjects were encouraged to undergo annual follow up examinations by total colonoscopy, irrespective of the results of previous examinations. Subjects undergoing a third or greater annual colonoscopies were entered into the analysis.

\section{Endoscopic procedures}

Two litres of polyethylene glycol electrolyte solution were ingested for bowel preparation. Medium length paediatric colonoscopes were used (mainly PCF200 and PCF230; Olympus, Tokyo, Japan). "Simple total colonoscopy" (no fluoroscopic assistance, no sedation or analgesia, one man method) was performed. During the procedure, the location and size of all polyps were determined and documented before their removal. The size of each polyp was estimated with open biopsy forceps $(=8 \mathrm{~mm})$. All polyps $\geqslant 5 \mathrm{~mm}$ and lesions $<5 \mathrm{~mm}$ suspected of neoplasia were resected 
endoscopically or by surgical operations. All pathological specimens were evaluated by the same pathologists at Kameda General Hospital. Neoplastic lesions were classified into colorectal invasive cancer, carcinoma in situ, and adenoma.

\section{Classification of subjects}

Subjects were classified into three groups according to the most advanced colorectal lesion found by the first and second colonoscopies. The first group consisted of subjects with no neoplastic lesions during the initial two colonoscopies. The second group consisted of subjects with small adenomas of $<10 \mathrm{~mm}$ at most. The third group consisted of subjects with advanced lesions, including carcinoma in situ, or with severe dysplasia, and adenomas $\geqslant 10 \mathrm{~mm}$. Subjects with invasive cancer were referred for medical care outside of our health check programme and were excluded from further analysis.

The incidence rate of colorectal adenomas was estimated by newly developed adenomas from subjects with no neoplastic lesions on the first two examinations. Recurrence rates of colorectal adenomas were estimated by newly detected adenomas after neoplasms were endoscopically resected either on the first or second colonoscopy. Two end points, all neoplastic lesions and advanced lesions, were subjected to analysis.

\section{Statistical analysis}

The incidence and recurrence rates of adenomas or advanced lesions were determined on the basis of the Kaplan-Meier method. Hazard ratios with $95 \%$ confidence intervals (CI) controlling for sex, age at the second colonoscopy, and initial colorectal lesions were calculated using the Cox proportional hazard model. A two sided p value of less than 0.05 was considered statistically significant. Analyses were performed with SAS for Windows software (SAS Institute Inc., North Carolina, USA).

\section{RESULTS}

Subjects and findings of the initial two colonoscopies A total of 68053 screening colonoscopies were performed from January 1988 to March 2002, of which 22395 were first time cases. Mean (SD) age was 48.1 (9.4) years; 15956 were men and 6439 were women. Of the total, 17933 (80.1\%) had no neoplastic lesions, 3699 (16.5\%) had small adenomas $<10 \mathrm{~mm}, 692(3.1 \%)$ had advanced lesions, including carcinoma in situ, severe dysplasia, or large adenomas $\geqslant 10 \mathrm{~mm}$, and $71(0.32 \%)$ had invasive carcinoma.

Among these, 7620 subjects underwent a second colonoscopy within 1.5 years after the first one, and $6356(83.4 \%)$ had no neoplasm, $1187(15.6 \%)$ had small adenomas, 74 $(0.97 \%)$ had advanced lesions, and three had invasive cancer at the second colonoscopy. When the results of the first and second procedures were combined, 5069 subjects (66.5\%) had no neoplasm, $2142(28.1 \%)$ had small adenomas, 393 $(5.2 \%)$ had advanced lesions, and $16(0.21 \%)$ had invasive carcinoma.

Of the 7604 subjects without invasive carcinoma, 6225 went on to have a third or more annual colonoscopies. Mean (SD) age at the second colonoscopy was 48.8 (8.4) years; 4659 were men and 1566 were women. Of these, 4084 subjects $(65.6 \%)$ had shown no neoplasm, 1818 (29.2\%) had shown small adenomas, and $323(5.2 \%)$ had shown advanced lesions during the initial two colonoscopies. The results of the third or more colonoscopies on these cohorts were analysed.

\section{Incidence and recurrence rates of colorectal neoplasms according to initial colonoscopic findings (table 1, fig 1)}

Of 4084 subjects with no neoplasm at the initial two colonoscopies, 848 (20.8\%) developed some type of colorectal neoplasm during a mean follow up of 2.89 years. The annual incidence rate was estimated to be $7.2 \%$.

Of 1818 subjects with small adenomas removed during the initial two colonoscopies, 821 (45.2\%) developed some type of colorectal neoplasm during a mean follow up period of 2.34 years. The annual recurrence rate was estimated to be $19.3 \%$.

Of 323 subjects with advanced lesions removed during the initial two colonoscopies, $162(50.2 \%)$ presented with some form of colorectal neoplasm during a mean follow up of 2.19 years, the annual recurrence rate being $22.9 \%$.

Hazard ratios controlling for sex and age of the subjects with no neoplasm initially were 2.4 (95\% CI 2.2-2.7; $\mathrm{p}<0.001)$ in those with small adenomas and 2.6 (2.2-3.1; $\mathrm{p}<0.001$ ) in those with advanced lesions.

\section{Incidence and recurrence rates of colorectal neoplasms according to sex and age}

Males or older subjects had a greater likelihood of developing more adenomas than females or younger subjects. The incidence or recurrence rates in males and females were $12.4 \%$ and $6.5 \% / y e a r$, respectively. Rates for the age groups $<40,40-49,50-59$, and $\geqslant 60$ years were $6.1 \%, 9.7 \%, 13.5 \%$, and $16.3 \% / y e a r$, respectively (table 1 ).

Sex and age were shown to be independent risk factors for newly developed colorectal neoplasias according to multivariate analysis. The male to female hazard ratio was 1.8 (95\% CI 1.6-2.0; $\mathrm{p}<0.001)$, and those for the age groups 40 $49,50-59$, and $\geqslant 60$ years relative to the $<40$ year age group were 1.5 (1.3-1.8; p<0.001), 2.0 (1.6-2.3; p <0.001), and 2.2 (1.8-2.7; $\mathrm{p}<0.001)$, respectively (table 1$)$.

When the group with no initial neoplasia was stratified by sex and age, the incidence rates of colorectal adenomas in male subjects were $4.7 \%, 8.2 \%, 10.1 \%$, and $11.4 \%$ year at ages $<40,40-49,50-59$, and $\geqslant 60$ years, respectively, and those in female subjects were $3.1 \%, 3.2 \%, 6.7 \%$, and $7.3 \% / y e a r$, respectively (table 2 ).

When the group with initial small adenomas was stratified by sex and age, the incidence rates of colorectal adenomas in males were $15.1 \%, 18.9 \%, 22.2 \%$, and $25.1 \% /$ year at age of $<40,40-49,50-59$, and $\geqslant 60$ years, respectively, and those in females were $7.9 \%, 11.4 \%, 14.1 \%$, and $20.4 \% / y e a r$, respectively (table 2).

Males with initial advanced lesions stratified by age had incidence rates of colorectal adenomas of $14.7 \%, 24.6 \%$, $26.7 \%$, and $24.4 \%$ year at $<40,40-49,50-59$, and $\geqslant 60$ years, respectively, and females had rates of $0.0 \%, 3.2 \%, 16.3 \%$, and $10.7 \%$ /year, respectively (table 2 ).

\section{Incidence and recurrence rates of advanced lesions according to initial colonoscopic findings (table 3, fig 2)}

Of 4084 subjects with no neoplasm found at the initial two colonoscopies, $30(0.73 \%)$ subjects developed advanced colorectal lesions during a mean follow up of 3.45 years. The annual incidence rate was estimated to be $0.21 \%$.

Of 1818 subjects with small adenomas removed at the initial two colonoscopies, $40(2.2 \%)$ developed advanced colorectal lesions during a mean follow up of 3.46 years. The annual recurrence rate was estimated to be $0.64 \%$.

Advanced lesions were removed from 323 subjects during the initial two colonoscopies, and during a mean follow up of 3.29 years, $20(6.2 \%)$ showed recurrence of advanced colorectal lesions, a rate of $1.88 \%$ year.

Hazard ratios controlling for sex and age of subjects with no initial neoplasm were 2.6 (95\% CI 1.6-4.2; p<0.001) in those with small adenomas and $6.6(3.7-12 ; \mathrm{p}<0.001)$ in those with advanced lesions. 
Table 1 Incidence and recurrence rates of colorectal neoplasia-all neoplasias

\begin{tabular}{|c|c|c|c|c|c|c|c|}
\hline & No of subjects & All neoplasias & Mean time $(y)$ & $\begin{array}{l}\text { Annual incidence } \\
\text { rate (\%/year) }\end{array}$ & $\begin{array}{l}\text { Hazard } \\
\text { ratio }\end{array}$ & $95 \% \mathrm{Cl}$ & p Value \\
\hline Total & 6225 & 1831 & 2.69 & 10.9 & & & \\
\hline \multicolumn{8}{|l|}{ Sex } \\
\hline Female & 1566 & 266 & 2.62 & 6.5 & 1 & & \\
\hline Male & 4659 & 1565 & 2.71 & 12.4 & 1.8 & $1.6-2.0$ & $<0.001$ \\
\hline \multicolumn{8}{|l|}{ Age $(y)^{*}$} \\
\hline$<40$ & 806 & 151 & 3.07 & 6.1 & 1 & & \\
\hline $40-49$ & 2738 & 754 & 2.84 & 9.7 & 1.5 & $1.3-1.8$ & $<0.001$ \\
\hline $50-59$ & 1975 & 656 & 2.46 & 13.5 & 2.0 & $1.6-2.3$ & $<0.001$ \\
\hline$\geqslant 60$ & 706 & 270 & 2.35 & 16.3 & 2.2 & $1.8-2.7$ & $<0.001$ \\
\hline \multicolumn{8}{|l|}{ Initial lesion } \\
\hline None & 4084 & 848 & 2.89 & 7.2 & 1 & & \\
\hline Small adenoma & 1818 & 821 & 2.34 & 19.3 & 2.4 & $2.2-2.7$ & $<0.001$ \\
\hline Advanced lesion & 323 & 162 & 2.19 & 22.9 & 2.6 & $2.2-3.1$ & $<0.001$ \\
\hline
\end{tabular}

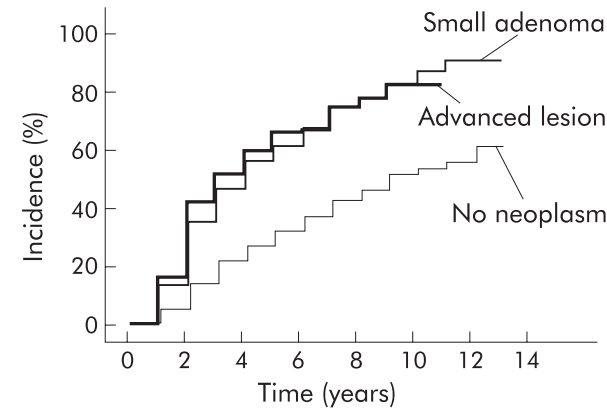

Figure 1 Cumulative incidence and recurrence rates of colorectal neoplasia according to initial lesions by the Kaplan-Meier method-all neoplasias.

\section{Incidence and recurrence rates of advanced lesions according to sex and age}

Older subjects were more likely to develop advanced lesions than younger subjects but there was no difference between the sexes. The incidence or recurrence rates in male and female subjects were $0.42 \%$ and $0.40 \% /$ year, respectively. Rates according to the age groups $<40,40-49,50-59$, and $\geqslant 60$ years were $0.10 \%, 0.29 \%, 0.56 \%$, and $0.97 \% /$ year, respectively (table 3 ).

Age, but not sex, was shown to be an independent risk factor for the new development of advanced lesions by multivariate analysis. The male to female hazard ratio was $0.9(95 \%$ CI $0.5-1.5 ; p=0.9)$, and those for the age groups
$40-49,50-59$, and $\geqslant 60$ years relative to that of the $<40$ year age group were $2.3(0.7-7.6 ; p=0.17), 3.6(1.1-12 ; p=0.04)$, and 5.5 (1.6-19; $\mathrm{p}<0.01$ ), respectively (table 3 ).

When the group with no initial neoplasia was stratified by sex and age, the incidence rates of advanced colorectal lesions in male subjects were $0.05 \%, 0.18 \%, 0.25 \%$, and $0.48 \%$ year at ages $<40,40-49,50-59$, and $\geqslant 60$ years, respectively, and those in female subjects were $0.00 \%$, $0.16 \%, 0.31 \%$, and $1.00 \% / y e a r$, respectively (table 4 ).

When the group with initial small adenomas was stratified by sex and age, the incidence rates of advanced colorectal lesions in males were $0.21 \%, 0.43 \%, 0.67 \%$, and $1.36 \%$ year at ages $<40,40-49,50-59$, and $\geqslant 60$ years, respectively, and those in females were $3.55 \%, 0.56 \%, 0.51 \%$, and $1.30 \% / y e a r$, respectively (table 4 ).

Males with initial advanced lesions stratified by age had incidence rates of advanced colorectal lesions of $0.00 \%$, $1.87 \%, 2.56 \%$, and $0.96 \% /$ year at $<40,40-49,50-59$, and $\geqslant 60$ years, respectively, and females had rates of $0.00 \%$, $0.00 \%, 2.05 \%$, and $2.26 \%$ year, respectively (table 4 ).

\section{Incidence and recurrence rates according to initial colonoscopic findings in subjects $\geqslant 50$ years old} Age groups $\geqslant 50$ years old consisting of 2681 subjects (males/ females 1918/763, mean age at second colonoscopy 56.8 years) were separately analysed according to initial colorectal findings. Colorectal cancer screening has been generally recommended for this population worldwide.

The annual incidence or recurrence rates of some type of colorectal neoplasm were 9.2\%/year (364/1507 cases during a

Table 2 Incidence and recurrence rates of colorectal neoplasia in detail-all neoplasias

\begin{tabular}{|c|c|c|c|c|c|}
\hline \multirow[b]{2}{*}{ Initial lesion } & \multirow[b]{2}{*}{ Sex } & \multicolumn{4}{|l|}{ Age group (y) } \\
\hline & & $<\mathbf{4 0}$ & $40-49$ & $50-59$ & $\geqslant 60$ \\
\hline \multirow[t]{4}{*}{ None } & Female & $3.1[1.3-6.3]$ & $3.2[2.4-4.2]$ & $6.7[5.4-8.4]$ & $7.3[4.5-11.3]$ \\
\hline & & $7 / 86 \times 2.66$ & $53 / 576 \times 2.90$ & $74 / 451 \times 2.46$ & $19 / 104 \times 2.50$ \\
\hline & Male & $4.7[3.9-5.9]$ & $8.2[7.5-9.2]$ & $10.1[9.0-11.7]$ & $11.4[9.1-14.2]$ \\
\hline & & $88 / 567 \times 3.28$ & $336 / 1348 \times 3.02$ & $198 / 722 \times 2.70$ & $73 / 230 \times 2.79$ \\
\hline \multirow[t]{4}{*}{ Small adenoma } & Female & $7.9[1.0-27.0]$ & $11.4[8.1-15.9]$ & $14.1[10.5-18.9]$ & $20.4[14.1-29.4]$ \\
\hline & & $2 / 11 \times 2.29$ & $33 / 117 \times 2.47$ & $42 / 121 \times 2.46$ & $25 / 56 \times 2.19$ \\
\hline & Male & $15.1[11.7-19.8]$ & $18.9[17.2-21.3]$ & $22.2[20.3-25.2]$ & $25.1[21.4-29.7]$ \\
\hline & & $51 / 130 \times 2.60$ & $289 / 606 \times 2.52$ & $264 / 543 \times 2.19$ & $115 / 234 \times 1.96$ \\
\hline \multirow[t]{4}{*}{ Advanced lesion } & Female & $0.0[0.0-70.8]$ & $3.2[0.1-16.7]$ & $16.3[6.4-32.8]$ & $10.7[3.0-25.4]$ \\
\hline & & $0 / 1 \times 3.01$ & $1 / 12 \times 2.63$ & $6 / 20 \times 1.84$ & $4 / 11 \times 3.38$ \\
\hline & Male & $14.7[3.2-37.9]$ & $24.6[18.8-32.4]$ & $26.7[22.0-33.1]$ & $24.4[17.8-32.9]$ \\
\hline & & $3 / 11 \times 1.86$ & $42 / 79 \times 2.16$ & $72 / 118 \times 2.28$ & $34 / 71 \times 1.96$ \\
\hline
\end{tabular}

Each cell represents "annual incidence rate (\%/year) [95\% confidence interval]" in the top row, and "number of cases with adenomas" / "number of subjects followed up " $x$ "mean follow up time (year)" in the bottom row. 
Table 3 Incidence and recurrence rates of colorectal neoplasia-advanced lesions

\begin{tabular}{|c|c|c|c|c|c|c|c|}
\hline & No of subjects & $\begin{array}{l}\text { Advanced } \\
\text { lesion }\end{array}$ & Mean time (y) & $\begin{array}{l}\text { Annual incidence rate } \\
\text { (\%/year) }\end{array}$ & Hazard ratio & $95 \% \mathrm{Cl}$ & p Value \\
\hline \multirow{2}{*}{\multicolumn{8}{|c|}{ Sex }} \\
\hline & & & & & & & \\
\hline Female & 1566 & 19 & 3.02 & 0.40 & 1 & & \\
\hline Male & 4659 & 71 & 3.59 & 0.42 & 0.9 & $0.5-1.5$ & 0.9 \\
\hline \multicolumn{8}{|l|}{ Age $(y)^{*}$} \\
\hline$<40$ & 806 & 3 & 3.56 & 0.10 & 1 & & \\
\hline $40-49$ & 2738 & 29 & 3.61 & 0.29 & 2.3 & $0.7-7.6$ & 0.17 \\
\hline $50-59$ & 1975 & 36 & 3.24 & 0.56 & 3.6 & $1.1-12$ & 0.04 \\
\hline$\geqslant 60$ & 706 & 22 & 3.22 & 0.97 & 5.5 & $1.6-19$ & $<0.01$ \\
\hline \multicolumn{8}{|l|}{ Initial lesion } \\
\hline None & 4084 & 30 & 3.45 & 0.21 & 1 & & \\
\hline Small adenoma & 1818 & 40 & 3.46 & 0.64 & 2.6 & $1.6-4.2$ & $<0.001$ \\
\hline Advanced lesion & 323 & 20 & 3.29 & 1.88 & 6.6 & $3.7-12$ & $<0.001$ \\
\hline
\end{tabular}

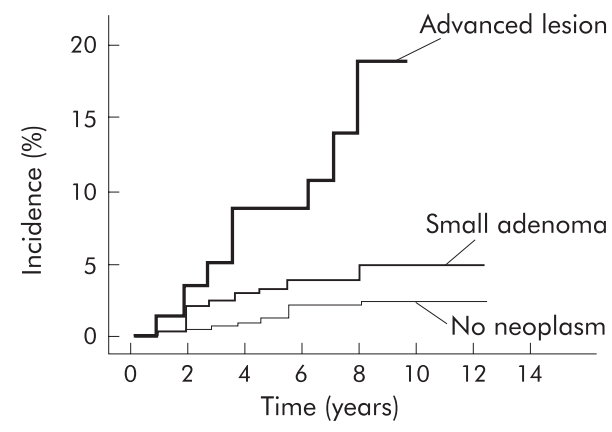

Figure 2 Cumulative incidence and recurrence rates of colorectal neoplasia according to initial lesions by the Kaplan-Meier methodadvanced lesions.

mean time of 2.63 years) in those with no neoplasm, $21.6 \% /$ year (446/954 over 2.17 years) in the small adenoma group, and $24.0 \% /$ year (116/220 over 2.17 years) in the advanced lesion group. Hazard ratios relative to those with no neoplasm initially were $2.2(95 \%$ CI $1.9-2.6$; $<<0.001)$ in those with small adenomas and $2.4(2.0-3.0 ; \mathrm{p}<0.001)$ in those with advanced lesions.

The annual incidence or recurrence rates of advanced lesion were $0.35 \% / y e a r$ ( $17 / 1507$ over 3.24 years) in those with no neoplasm, $0.85 \%$ /year (26/954 over 3.22 years) in the small adenoma group, and 2.05\%/year (15/220 over 3.32 years) in the advanced lesion group. Hazard ratios relative to those with no neoplasm initially were 2.3 (95\% CI
$1.2-4.3 ; \mathrm{p}<0.001)$ in those with small adenomas and 5.3 $(2.6-11 ; \mathrm{p}<0.001)$ in those with advanced lesions.

\section{DISCUSSION}

Studies on the endoscopic surveillance of patients at high risk have reported high recurrence rates of colorectal adenomas after polyp removal. Recurrence rates of $15-60 \%$ within 3-4 years after previous polypectomy have been reported..$^{74-17}$ Sex, age, index adenoma size, number, and pathology have also been reported as risk factors involved in higher recurrence rates of colorectal adenomas. ${ }^{74-17}$ Our results were in general agreement with these reports. Recurrence rates of colorectal neoplasm were estimated to be $19.3 \% /$ year in those with small adenomas and $22.9 \%$ /year in those with advanced lesions.

Little is known of the incidence rates of colorectal adenomas in those who are free of neoplasms at their initial examination although they are widely believed to be lower than recurrence rates following polypectomy. ${ }^{18}$ In previous studies, Neugut and colleagues ${ }^{18}$ reported a cumulative incidence rate of $16 \%$ among 99 subjects at three years, and Rex and colleagues, ${ }^{19}$ following 154 subjects for a mean of 5.5 years, reported an incidence rate of $27 \%$. Certainly, incidence rates were generally lower than recurrence rates but they seemed to be extremely high compared with those of invasive cancer from post-polypectomy subjects who were thought to be at high risk (reported to be $0.3-0.5 \%$ at 3 years $)^{7}$

Significant miss rates of single colonoscopies, especially for small adenomas, have been estimated on the basis of tandem

\begin{tabular}{|c|c|c|c|c|c|}
\hline \multirow[b]{2}{*}{ Initial lesion } & \multirow[b]{2}{*}{ Sex } & \multicolumn{4}{|l|}{ Age group } \\
\hline & & $<40$ & $40-49$ & $50-59$ & $\geqslant 60$ \\
\hline \multirow[t]{4}{*}{ None } & Female & 0.00 [0.00-1.53] & $0.16[0.03-0.49]$ & $0.31[0.09-0.80]$ & $1.00[0.21-2.94]$ \\
\hline & & $0 / 86 \times 2.82$ & $3 / 576 \times 3.16$ & $4 / 451 \times 2.88$ & $3 / 104 \times 2.88$ \\
\hline & Male & $0.05[0.00-0.27]$ & $0.18[0.08-0.34]$ & $0.25[0.09-0.54]$ & $0.48[0.13-1.23]$ \\
\hline & & $1 / 567 \times 3.69$ & $9 / 1348 \times 3.75$ & $6 / 722 \times 3.39$ & $4 / 230 \times 3.63$ \\
\hline \multirow[t]{4}{*}{ Small adenoma } & Female & $3.55[0.09-19.0]$ & $0.56[0.07-2.02]$ & $0.51[0.06-1.84]$ & $1.30[0.16-4.73]$ \\
\hline & & $1 / 11 \times 2.56$ & $2 / 117 \times 3.08$ & $2 / 121 \times 3.26$ & $2 / 56 \times 2.75$ \\
\hline & Male & $0.21[0.01-0.19]$ & $0.43[0.21-0.79]$ & $0.67[0.35-1.18]$ & $1.36[0.66-2.52]$ \\
\hline & & $1 / 130 \times 3.65$ & $10 / 606 \times 3.88$ & $12 / 543 \times 3.30$ & $10 / 234 \times 3.14$ \\
\hline \multirow{4}{*}{ Advanced lesion } & Female & $0.00[0.00-70.8]$ & $0.00[0.00-10.3]$ & $2.05[0.05-11.1]$ & $2.26[0.06-12.0]$ \\
\hline & & $0 / 1 \times 3.01$ & $0 / 12 \times 2.88$ & $1 / 20 \times 2.44$ & $1 / 11 \times 4.03$ \\
\hline & Male & $0.00[0.00-12.3]$ & $1.87[0.62-4.38]$ & $2.56[1.30-4.58]$ & $0.96[0.12-3.46]$ \\
\hline & & $0 / 11 \times 2.59$ & $5 / 79 \times 3.38$ & $11 / 118 \times 3.64$ & $2 / 71 \times 2.93$ \\
\hline
\end{tabular}

Each cell represents "annual incidence rate (\%/year) [95\% confidence interval]" in the top row, and "number of cases with adenomas" / "number of subjects followed up " $x$ "mean follow up time (year)" in the bottom row. 
colonoscopies. ${ }^{20} 22$ Miss rates of $15-24 \%$ for all types of adenomas and $0-6 \%$ for adenomas $\geqslant 10 \mathrm{~mm}$ have been reported. Therefore, the studies cited above regarding the incidence rates of adenomas from the normal colon assumed that many of the detected adenomas had probably been missed in the initial procedure. ${ }^{18} 19$ In fact, since they evaluated incidence rates only from the results of second follow up colonoscopies, ${ }^{18}{ }^{19}$ a considerable number of missed lesions must have been blended into the results, and the actual contribution of missed lesions to the incidence rates is uncertain. In order to avoid this obfuscating problem of missed neoplasms as much as possible in the present study, we performed two serial colonoscopies, using the second to confirm the findings of the first. Then the incidence and recurrence rates were determined from the results of the third or even more colonoscopies.

In our study, even subjects with no initial neoplasm showed an incidence rate of colorectal neoplasm of as much as $7.2 \%$ /year. Moreover, the yearly incidence rate seemed constant according to the Kaplan-Meier curve. The present study is, to our knowledge, the largest in terms of number of subjects, and the most precise that has ever been reported on this topic. We believe that this high incidence of colorectal neoplasm reflects the actual situation, at least in the Japanese population. Colorectal adenomas are much more common lesions than colorectal cancers, as a high prevalence has also been reported by screening colonoscopy studies. $^{9-11} 1323$

The incidence and recurrence rates of all adenomas were associated with sex and age in our study. The association of incidence rates with sex and age was not significant in previous studies, perhaps because of small sample size or ${\text { other biases. }{ }^{18} 19}^{19}$ Our results paralleled those of prevalence studies. ${ }^{9-1123}$ It can be concluded that colorectal adenomas are more likely to develop in males and in older subjects. When considering only advanced lesions, association with sex was uncertain. This may be due to sample size or it may be related to a rising risk in female subjects as they grow older.

On the basis of the extremely high incidence and recurrence rates of colorectal neoplasia, small adenomas would seem to be a common disease. The result may be too high even when compared with the high prevalence obtained from cross sectional studies. ${ }^{9-1123}$ Hofstad and colleagues ${ }^{24}$ suggested the possibility of regression of small adenomas, which may partly explain our observation. On the other hand, the development of advanced lesions was highly correlated with the initial colorectal findings. It was much more likely to develop in the subject with a past history of colorectal adenoma, and especially with a history of an advanced stage. In fact, advanced lesions might be better candidates as a target of colorectal cancer screening and surveillance programmes instead of all neoplastic lesions, including small adenomas. ${ }^{825}$

\section{Authors' affiliations \\ Y Yamaji, H Watabe, M Okamoto, Division of Gastroenterology, Department of Internal Medicine, University of Tokyo, and Makuhari Clinic, Tokyo, Japan \\ T Mitsushima, H Ikuma, Department of Gastroenterology, Kameda General Hospital, and Makuhari Clinic, Tokyo, Japan \\ T Kawabe, M Omata, Division of Gastroenterology, Department of Internal Medicine, University of Tokyo, Tokyo, Japan}

R Wada, Department of Gastroenterology, Kameda General Hospital, Tokyo, Japan

H Doi, Makuhari Clinic, Tokyo, Japan

\section{REFERENCES}

1 Muto T, Bussey HJ, Morson BC. The evolution of cancer of the colon and rectum. Cancer 1975:36:2251-70.

2 Vogelstein B, Fearon ER, Hamilton SR, et al. Genetic alterations during colorectal-tumor development. N Engl J Med 1988;319:525-32.

3 Mandel JS, Bond JH, Church TR, et al. Reducing mortality from colorectal cancer by screening for fecal occult blood. Minnesota Colon Cancer Control Study. N Engl J Med 1993;328:1365-71.

4 Hardcastle JD, Chamberlain JO, Robinson MH, et al. Randomised controlled trial of faecal-occult-blood screening for colorectal cancer. Lancet 1996;348:1472-7.

5 Kronborg O, Fenger C, Olsen J, et al. Randomised study of screening for colorectal cancer with faecal-occult-blood test. Lancet 1996;348:1467-71.

6 Winawer SJ, Zauber AG, Ho MN, et al. Prevention of colorectal cancer by colonoscopic polypectomy. The National Polyp Study Workgroup. N Engl J Med 1993;329:1977-81.

7 Winawer SJ, Zauber AG, O'Brien MJ, et al. Randomized comparison of surveillance intervals after colonoscopic removal of newly diagnosed adenomatous polyps. The National Polyp Study Workgroup. N Engl J Med 1993;328:901-6.

8 Rex DK, Johnson DA, Lieberman DA, et al. Colorectal cancer prevention 2000: screening recommendations of the American College of Gastroenterology. American College of Gastroenterology. Am J Gastroenterol 2000;95:868-77.

9 Rex DK, Lehman GA, Ulbright TM, et al. Colonic neoplasia in asymptomatic persons with negative fecal occult blood tests: influence of age, gender, and family history. Am J Gastroenterol 1993;88:825-31.

10 Lieberman DA, Weiss DG, Bond JH, et al. Use of colonoscopy to screen asymptomatic adults for colorectal cancer. Veterans Affairs Cooperative Study Group 380. N Engl J Med 2000;343:162-8.

11 Imperiale TF, Wagner DR, Lin CY, et al. Risk of advanced proximal neoplasms in asymptomatic adults according to the distal colorectal findings. N Engl J Med 2000;343:169-74

12 Okamoto M, Shiratori Y, Yamaii Y, et al. Relationship between age and site of colorectal cancer based on colonoscopy findings. Gastrointest Endosc 2002;55:548-51.

13 Sung JJ, Chan FK, Leung WK, et al. Screening for colorectal cancer in Chinese: comparison of fecal occult blood test, flexible sigmoidoscopy, and colonoscopy. Gastroenterology 2003;124:608-14.

14 van Stolk RU, Beck GJ, Baron JA, et al. Adenoma characteristics at first colonoscopy as predictors of adenoma recurrence and characteristics at follow-up. The Polyp Prevention Study Group. Gastroenterology 1998; 115:13-18.

15 Noshirwani KC, van Stolk RU, Rybicki LA, et al. Adenoma size and number are predictive of adenoma recurrence: implications for surveillance colonoscopy. Gastrointest Endosc 2000;51:433-7.

16 Martinez ME, Sampliner R, Marshall JR, et al. Adenoma characteristics as risk factors for recurrence of advanced adenomas. Gastroenterology 2001; 120:1077-83.

17 Nusko G, Mansmann U, Kirchner T, et al. Risk related surveillance following colorectal polypectomy. Gut 2002;51:424-8.

18 Neugut Al, Jacobson JS, Ahsan $\mathrm{H}$, et al. Incidence and recurrence rates of colorectal adenomas: a prospective study. Gastroenterology 1995; 108:402-8.

19 Rex DK, Cummings OW, Helper DJ, et al. 5-year incidence of adenomas after negative colonoscopy in asymptomatic average-risk persons. Gastroenterology 1996;111:1178-81.

20 Hixson L, Fennerty MB, Sampliner RE, et al. Prospective blinded trial of the colonoscopic miss-rate of large colorectal polyps. Gastrointest Endosc 1991;37:125-7.

21 Rex DK, Rahmani EY, Haseman JH, et al. Relative sensitivity of colonoscopy and barium enema for detection of colorectal cancer in clinical practice. Gastroenterology 1997;112:17-23.

22 Rex DK, Cutler CS, Lemmel GT, et al. Colonoscopic miss rates of adenomas determined by back-to-back colonoscopies. Gastroenterology 1997; 112:24-8.

23 Imperiale TF, Wagner DR, Lin CY, et al. Results of screening colonoscopy among persons 40 to 49 years of age. N Engl J Med 2002;346:1781-5.

24 Hofstad B, Vatn MH, Andersen SN, et al. Growth of colorectal polyps: redetection and evaluation of unresected polyps for a period of three years. Gut 1996;39:449-56.

25 Winawer S, Fletcher R, Rex D, et al. Colorectal cancer screening and surveillance: clinical guidelines and rationale-update based on new evidence. Gastroenterology 2003;124:544-60. 